\title{
Decomposition of Protonated Formic Acid: One Transition State-Two Product Channels
}

\author{
Osamu Sekiguchi, Vebjørn Bakken, and Einar Uggerud \\ Department of Chemistry, University of Oslo, Oslo, Norway
}

The unimolecular chemistry of protonated formic acid, $[\mathrm{HCOOH}] \mathrm{H}^{+}$, has been investigated by analyzing the fragmentation of metastable ions (MI) during flight in a sector mass spectrometer, and by proton transfer to formic acid in a Fourier-transform ion cyclotron resonance (FT-ICR) mass spectrometer. High level ab initio calculations have been used to model the relevant parts of the potential energy surface (PES). In addition, ab initio direct dynamics calculations have been conducted, tracing out 60 different reaction trajectories. The only stable isomer in the mass spectrometric experiments is $\mathrm{HC}(\mathrm{OH})_{2}^{+}$, which is the precursor to both observed ionic products, $\mathrm{HCO}^{+}$and $\mathrm{H}_{3} \mathrm{O}^{+}$, via the same saddle point of the potential energy surface. The detailed motion of the dissociating molecule during passage of the post-transition state region of the PES therefore determines which product ion is formed. After passing the TS a transient $\mathrm{HC}(\mathrm{O}) \mathrm{OH}_{2}^{+}$molecule is first formed. High total energy increases the probability that the nascent water molecule will have sufficient speed to escape the $\mathrm{HCO}^{+}$moiety. Otherwise, typically at low energies, the two units recombine, upon which intra-complex proton transfer is very likely. Eventually, this will give the more stable $\mathrm{H}_{3} \mathrm{O}^{+}$. (J Am Soc Mass Spectrom 2004, 15, 982-988) (c) 2004 American Society for Mass Spectrometry

$\mathrm{I}$

n 1978 Mackay et al. [1] reported that proton transfer from $\mathrm{H}_{3}^{+}$to formic acid leads to two different ionic products (Scheme 1):

Under their conditions, the product distribution was $\left[\mathrm{HCO}^{+}\right]:\left[\mathrm{H}_{3} \mathrm{O}^{+}\right]=7: 3$. Metastable ions of protonated

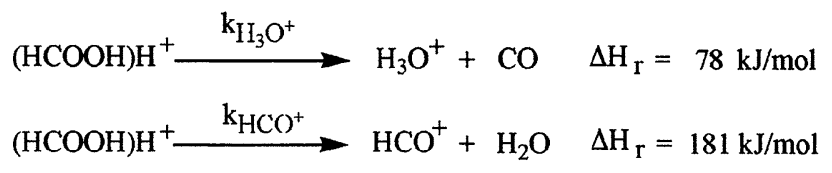

Scheme 1

formic acid decompose to give both the hydroxonium ion $(m / z ~ 19)$ and the formyl ion $(m / z 29)$ [2, 3]. The observation of two products channels in this case, differing in reaction endothermisities by $100 \mathrm{kJmol}^{-1}$, appears to be incompatible with thermochemical product control. Protonated formic acid has two tautomers: $\mathrm{HC}(\mathrm{OH})_{2}^{+}(\mathbf{1})$ and $\mathrm{HCOOH}_{2}^{+}$(2), the former being the more stable (See Figure 1 for structural assignments) [4]. Thus the above observation could be better interpreted as a situation where both tautomers are present, and where each gives rise to one product. However, this is not in accord with the results of ab initio calculations,

Published online June 10, 2004

Dedicated to Fred W. McLafferty, Recipient of the 2003 ASMS Distinguished Contribution in Mass Spectrometry Award.

Address reprint requests to Dr. E. Uggerud, Department of Chemistry, University of Oslo, P.O. Box 1033 Blinden, N-0315 Oslo, Norway. E-mail: einar.uggerud@kjemi.uio.no since the barrier for formation of $\mathrm{H}_{3} \mathrm{O}^{+}+\mathrm{CO}$ from $\mathrm{HCOOH}_{2}^{+}$amounts to only a few $\mathrm{kJmol}^{-1}[5,6]$, a finding which casts doubt on the existence of this isomer in the metastable ion time frame. Holmes et al. reported identical $(13.7 \pm 0.2 \mathrm{eV})$ appearance energies for $\mathrm{H}_{3} \mathrm{O}^{+}$and $\mathrm{HCO}^{+}$from decomposition of metastable $\left[\mathrm{C}, \mathrm{H}_{3}, \mathrm{O}_{2}\right]^{+}$derived from ethyl formate [2], suggesting a common transition state for the two processes. These authors only observed $\mathrm{DCO}^{+}$, and no $\mathrm{HCO}^{+}$, from $\mathrm{DC}(\mathrm{OH})_{2}^{+}$indicating a rate determining 1,3-hydrogen shift. Glosik et al. showed complementary evidence in that $[\mathrm{HCOOH}] \mathrm{D}^{+}$decomposes to give $\mathrm{HCO}^{+}$and $\mathrm{H}_{2} \mathrm{DO}^{+}$, but not $\mathrm{DCO}^{+}[7]$.

It is also appropriate to mention that protonated formic acid present in superacid solution has structure $\mathbf{1}$ at low temperatures. Upon heating, there is evidence for isomerization to 2 followed by decomposition $[8,9]$.

The purpose of the present study is to understand which factors govern the product distribution in a reaction where both products are formed via the same transition state. In order to study the reaction dynamics in more detail, we employed mass-analyzed ion kinetic energy (MIKE) spectrometry and Fourier transform ion cyclotron resonance (FT-ICR) mass spectrometry. In addition, the reactions were modeled using ab initio direct dynamics calculations.

\section{Experimental}

MI and CID spectra were recorded using a Fisons (Manchester, UK) Prospec-Q, which is a hybrid mass spectrometer with EBEHQ configuration normally run- 


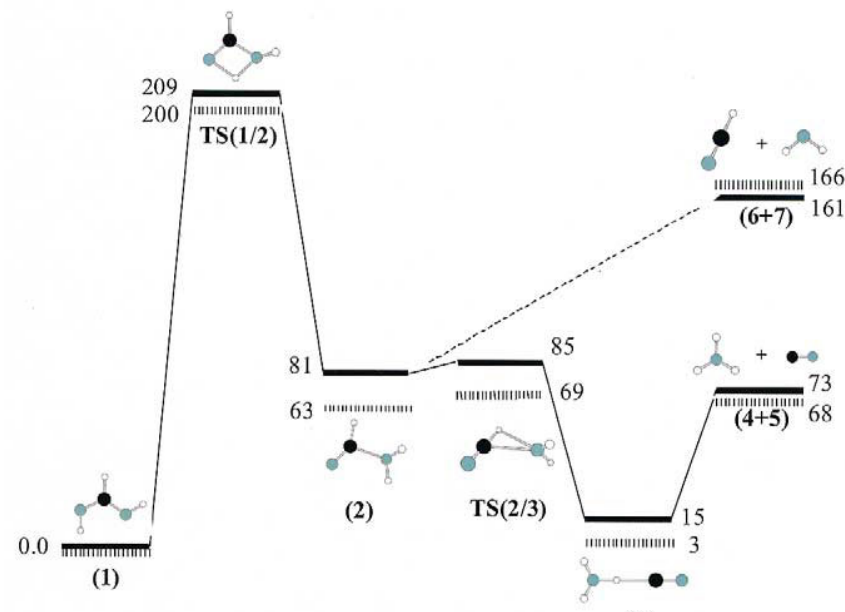

(3)

Figure 1. Potential energy surfaces of the decomposition of protonated formic acid obtained with G2 (stationary structures marked with fat full line) and MP2(fc)/6-31G(d) (stationary structures marked with fat dotted line). The saddle point $\mathbf{T S}\left(2 / 2^{\prime}\right)$ which connects 2 with its mirror image $2^{\prime}$ via a libration of the $\mathrm{H}_{2} \mathrm{O}$ moiety is omitted from the figure.

ning at an acceleration voltage of $8 \mathrm{kV}$. The precursor ion of interest was selected using the first two stages (EB). Ionic decomposition products were recorded with an orthogonal detector positioned in the fourth field free region, by scanning the second electric sector. For the electron impact (EI) experiments with ethyl formate the electron energy was $70 \mathrm{eV}$. For chemical ionization (CI), $\mathrm{CH}_{4}$ was used as a reagent gas, and a particularly tight ion source was used to ensure high pressure conditions. Collisionally induced dissociation (CID) was achieved by bringing the selected precursor ions to collide with He in the third field free region (after B). The He pressure inside the collision cell was set to attenuate the intensity of the precursor ion peak to ca. $30 \%$.

The FT-ICR experiments were performed with a Bruker (Billerica, MA) Apex 47 mass spectrometer. Selected proton donor ions $\left(\mathrm{MH}^{+}\right)$were produced in the external EI/CI source, and transferred into the ICR cell where formic acid at low pressure was charged through a leak valve at a constant pressure in the range $2 \times 10^{-9}-1.4 \times 10^{-8}$ mbar. All ions except $\mathrm{MH}^{+}$were ejected using sweep pulses followed by clean-up shot pulses. Mass spectra were recorded after a variable reaction time, $t_{r}$, thereby giving the reactant and product ion distributions with time. Pseudo-firstorder bimolecular rate constants for the total consumption of $\mathrm{MH}^{+}$were taken from the slope of the straight lines obtained by plotting the natural logarithm of the normalized ion intensities against $t_{r}$. The longest reaction time measured was $3 \mathrm{~s}$. The properties of the proton donors, $\mathrm{MH}^{+}$, used are given in Table 1.
Table 1. Proton donors used in FT-ICR experiments

\begin{tabular}{|c|c|c|c|}
\hline $\mathrm{MH}^{+}$ & M & $\triangle P A$ & Method of production \\
\hline $\mathrm{HI}^{+}$ & 1 & 133.8 & electron ionization of $\mathrm{NH}_{4} \mathrm{I}$ \\
\hline $\mathrm{H}_{2} \mathrm{Cl}^{+}$ & $\mathrm{HCl}$ & 185.1 & $\begin{array}{l}\mathrm{CH}_{5}{ }^{+} \text {chemical ionization of } \mathrm{NH}_{4} \mathrm{Cl} \text { to } \\
\text { produce } \mathrm{H}_{2} \mathrm{Cl}^{+}\end{array}$ \\
\hline $\mathrm{CH}_{5}^{+}$ & $\mathrm{CH}_{4}$ & 198.5 & $\mathrm{CH}_{4}$ chemical ionization \\
\hline $\mathrm{HCO}_{2}{ }^{+}$ & $\mathrm{CO}_{2}$ & 201.5 & electron ionization of $\mathrm{HCOOH}$ \\
\hline $\mathrm{HCl}^{+}$ & $\mathrm{Cl}^{2}$ & 228.4 & electron ionization of $\mathrm{NH}_{4} \mathrm{Cl}$ \\
\hline
\end{tabular}

$\triangle P A=P A(\mathrm{M})-P A(\mathrm{HCOOH})$, where $P A$ is the proton affinity in $\mathrm{kJmol}^{-1}$. The values have been taken from reference [28], and the uncertainties are likely to be within $10 \mathrm{kJmol}^{-1} \cdot P A(\mathrm{HCOOH})=228.4 \mathrm{kJmol}^{-1}$.

\section{Theoretical}

The relevant part of the $[\mathrm{HCOOH}] \mathrm{H}^{+}$potential energy surface was probed at various theoretical levels with the GAUSSIAN 98 suite [10]. Methods used include HF theory, MP2 and Becke 3-parameter Lee-Yang-Parr (B3LYP) DFT employing among others, 4-31G and 6-31G(d) basis sets. For each level of theory all stationary points were subject to a complete geometry optimisation, including a check for the correct number of negative Hessian eigenvalues. At this stage, analytical force constants were computed and the vibrational harmonic frequencies were obtained together with the rotational constants. From these calculated spectroscopic constants, zero-point vibrational energies and thermochemical quantities were calculated within the rigid-rotor/harmonic-oscillator approximation. Zeropoint vibrational energies were included with appropriate scaling factors [11]. The connectivity of a saddle point to reactant/product was checked by IRC calculations [12]. In addition, G2 theory [13] calculations were used to obtain the most accurate energy estimates. G2 theory is a compound technique which involves initial geometry optimizations at the HF/6-31G(d) level and subsequent calculation of zero point vibrational energies (ZPVEs) at the same level of theory. Then the geometry is re-optimized at the MP2(full)/6-31G(d) level whereupon a number of single-point MP2, MP4, and QCISD(T) calculations are performed in order to obtain an energy estimate which is effectively at the QCISD(T)/6-311 + G(3df,2p) level.

The direct ab initio approach to trajectory calculations utilizes the first and second derivatives of the electronic energy with respect to atomic displacements (gradients and Hessians) to generate molecular trajectories $\boldsymbol{q}(t)=\{\boldsymbol{q}(t), \boldsymbol{q}(t), \ldots\}$ within the Born-Oppenheimer approximation [14-17]. For efficiency, the trajectory is calculated using a fifth-order predictorcorrector method, based on the repeated calculation of the wave function and its geometrical derivatives at points $\boldsymbol{q}_{\mathrm{i}}$ in time steps, typically varying between 0.2 and $0.5 \mathrm{fs}$. The energy and the molecular gradient are calculated at every point, whereas the Hessian is recalculated at every fifth point, being updated at the intermediate points. Each trajectory was calculated "onthe-fly" by a stepwise procedure calculating MP2(fc)/ 


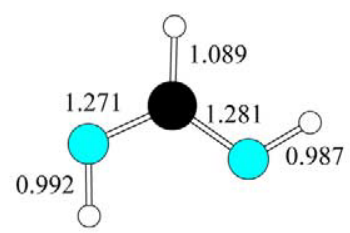

$1(C s)$

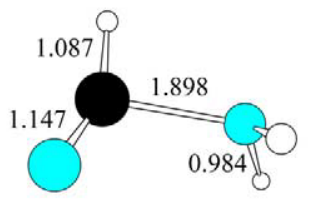

$\operatorname{TS}\left(2 / 2^{\prime}\right)(C s)$

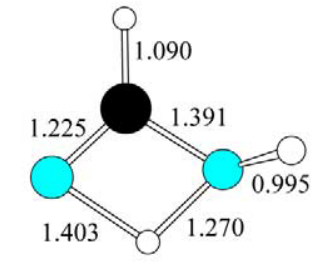

$\operatorname{TS}(1 / 2) \quad\left(C_{l}\right)$

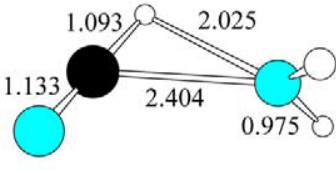

$\operatorname{TS}(2 / 3) \quad(C s)$

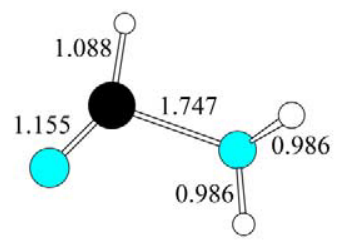

$2\left(C_{l}\right)$

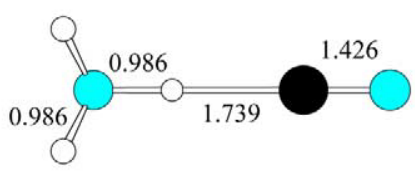

3 (Cs)
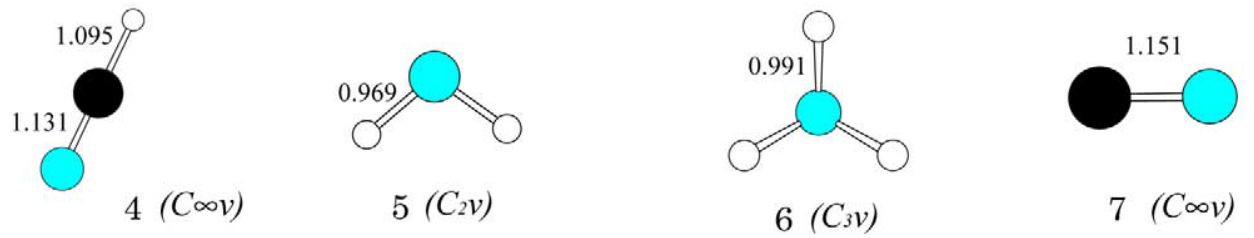

Figure 2. Optimized structures at the MP2(fc) $/ 6-31 \mathrm{G}(\mathrm{d})$ level. Bond lengths are given in $\AA$.

6-31G(d) wave functions at each point, starting from TS(1/2) (vide infra). Vibrational and rotational degrees of freedom were sampled from ensembles at 298 and $1000 \mathrm{~K}$, respectively, and the transition mode was sampled thermally [18]. For each temperature, 30 different trajectories were calculated.

A standard procedure was used for the RRKM calculations [19]. The scaled vibrational frequencies from MP2(fc)/6-31G(d) calculations were used as input.

\section{Results and Discussion}

\section{Potential Energy Surfaces}

The $\left[\mathrm{C}, \mathrm{H}_{3}, \mathrm{O}_{2}\right]^{+}$potential energy surface has been the subject of several experimental [1, 2, 7, 20-25] and theoretical $[4-6,26,27]$ studies, of which the most salient features have been reviewed in the introduction.

For this study we found it necessary to construct a reference potential energy diagram of high accuracy, in accordance with and describing the relevant parts of the known unimolecular reactivity of protonated formic acid. The G2 theory diagram, identical to that of Cheung and Li [6] is reproduced in Figure 1. It fulfils the object of reproducing the appropriate experimental heats of formation [28] within $10 \mathrm{kJmol}^{-1}$, and the relative energies are also very close to those of a recent CBS-QB3 study [5]. One may note that the MP2/6$31 \mathrm{G}(\mathrm{d})$ energies also included in this diagram are in good agreement with the benchmark G2 values. This will be an important point in the preceding dynamic calculations.* The structures of all species involved (MP2(fc)/6-31G(d)) are shown in Figure 2.

The reference point of Figure 1 is the most stable stereoisomeric form of carbonyl protonated formic acid, Structure 1. The fact that the carbonyl oxygen is more basic than the hydroxyoxygen was noted already in the 1960s $[4,8,20,29-31]$, and is in accordance with a general trend for similar carbonyl compounds [32, 33]. It is also interesting that structure $\mathbf{1}$ recently was isolated and characterized in the solid state in the form of $\mathrm{HC}(\mathrm{OH})_{2}^{+} \mathrm{AsF}_{6}^{-}$[9].

The second tautomer of protonated formic acid, the hydroxyl protonated form, $\mathbf{2}$, is considerably higher in potential energy. It is also noteworthy that the two tautomers are separated by a barrier of $209 \mathrm{kJmol}^{-1}$ via TS(1/2). It will be evident that this TS, formally representing a 1,3-intramolecular proton transfer, is the key to the dynamics of the unimolecular fragmentation of protonated formic acid.

A third isomer, which should be regarded as a hydrogen bonded complex between the hydroxonium ion and carbon monoxide, $\mathrm{OH}_{3}^{+} \ldots \mathrm{CO}(3)$, is only 15 $\mathrm{kJmol}^{-1}$ higher in potential energy than 1 . Except for the aforementioned quantum chemical calculation, there seems to be little literature on 3 . It was subject to CID and neutralization-reionization (NR) in a study by

*We were concerned about how well the 6-31G(d) basis provides sufficiently accurate structures of ion/molecule complexes. In the case of 2 , $\mathrm{MP} 2 / 6-31++\mathrm{G}(\mathrm{d}, \mathrm{p})$ gave a $0.3 \AA$ longer $\mathrm{C}-\left(\mathrm{OH}_{2}\right)$ bond than $\mathrm{MP} 2 / 6$ $31 \mathrm{G}(\mathrm{d})$. However, this structural difference only affects relative energies by about $1 \mathrm{kJmol}^{-1}$. 


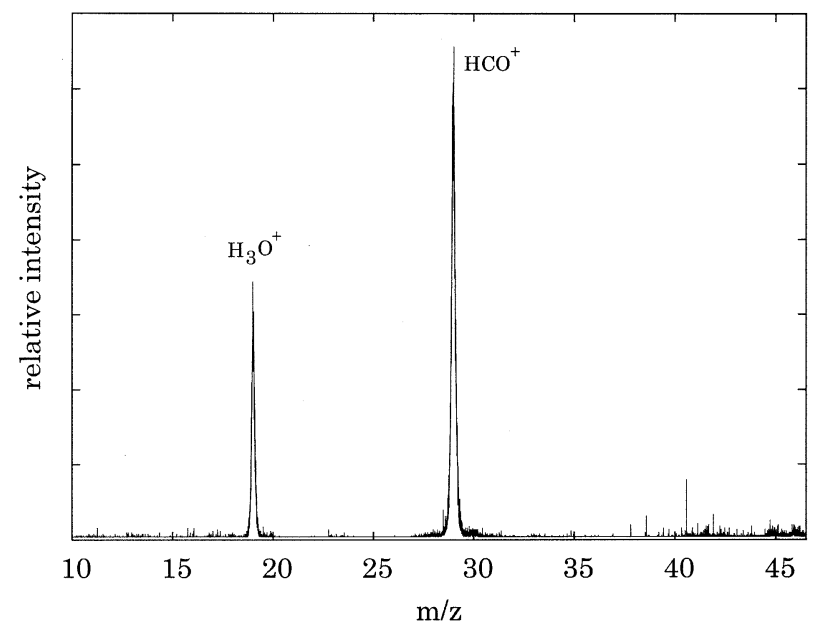

Figure 3. MI spectrum of $[\mathrm{HCOOH}] \mathrm{H}^{+}$produced by chemical ionization, using $\mathrm{CH}_{4}$ at $\mathrm{p}=2.9 \times 10^{-5}$ mbar.

Schalley et al. [25]. The CID spectrum is different from that of $\mathbf{1}$, by showing a strong signal for CO loss. The NR spectra are also different. It appears that $\mathbf{1}$ in contrast to 3 gives rise to a recovery signal. On the basis of this discussion, we may conclude that the complex $\mathrm{OH}_{3}^{+} \ldots \mathrm{CO}(3)$ is the precursor for $\mathrm{H}_{3} \mathrm{O}^{+}+\mathrm{CO}$ product pair, while $\mathrm{HC}(\mathrm{O}) \mathrm{OH}_{2}^{+}$connects to $\mathrm{HCO}^{+}+\mathrm{H}_{2} \mathrm{O}$.

The two product channels, $\mathrm{HCO}^{+}+\mathrm{H}_{2} \mathrm{O}$ and $\mathrm{H}_{3} \mathrm{O}^{+}$ $+\mathrm{CO}$, differ in potential energy by the difference in proton affinity between carbon monoxide and water. The calculated differences of $89 \mathrm{kJmol}^{-1}$ (G2) and 98 $\mathrm{kJmol}^{-1}$ (MP2) are close to the experimental value (97 \pm $25 \mathrm{kJmol}^{-1}$ ) [28]. The barrier for decomposition of 2 into $\mathrm{H}_{3} \mathrm{O}^{+}+\mathrm{CO}$ is extremely low $\left\{4 \mathrm{kJmol}^{-1}\right.$ (G2) and 6 $\mathrm{kJmol}^{-1}$ (MP2)\}.

The IRC from TS(2/3) ends in 3 on one side, and the saddle point $\operatorname{TS}\left(2 / \mathbf{2}^{\prime}\right)$ for librational motion within 2 on the other (see caption of Figure 1). This is not an artefact, and this type of IRC-connectivity between two saddle point has been reported previously in a few cases [34-36]. However, this is not a particularly important detail of the PES with regards to the dynamics of dissociation.

\section{$M I$ and CID Experiments}

The MI spectrum of protonated formic acid produced from ethyl formate upon EI showed the intensity ratio $\left(\mathrm{I}_{\mathrm{HCO}+} / \mathrm{I}_{\mathrm{H} 3 \mathrm{O}+}\right)=1.3$. This is nearly the same as reported earlier [2, 3]. In the MI spectrum of protonated formic acid produced by $\mathrm{CI}$ of formic acid (Figure 3 ), the ratio $\mathrm{I}_{\mathrm{HCO}}+\mathrm{I}_{\mathrm{H} 3 \mathrm{O}}+$ is larger than that in the MI spectrum, and it increases linearly with the pressure of the reagent gas $\left(\mathrm{CH}_{4}\right)$-from $\left(\mathrm{I}_{\mathrm{HCO}+} / \mathrm{I}_{\mathrm{H} 3 \mathrm{O}+}\right)=2.1$ at $2.9 \times 10^{-5}$ mbar to 7.4 at $1.1 \times 10^{-4}$ mbar (the pressure was monitored outside the ion source). The ratio extrapolated to zero pressure is 0.6. The relative abundance of distribution of proton donor ions $\left(\mathrm{CH}_{5}^{+} / \mathrm{C}_{2} \mathrm{H}_{5}^{+}\right)$in the $\mathrm{CH}_{4}$ plasma did not change within the pressure range indicated above. Higher pressure will partly give rise to a situation with

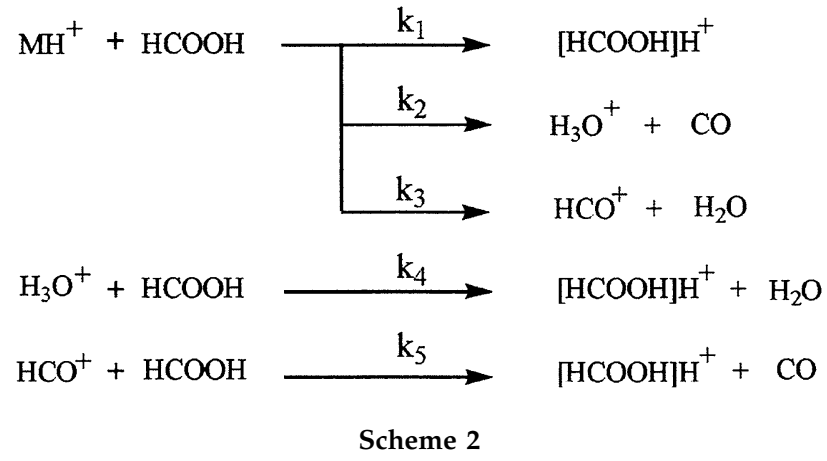

better equilibration of protonated formic acid species before they leave the ion source. This will probably favor formation of the carbonyl protonated molecule relative to the isomeric species. At the same time, a higher pressure in the ion source will lead to an increased pressure outside, which increases the possibility for unintentional CID. Without having investigated the phenomenon in greater detail, our impression is that unintentional CID is the major effect.

Both the CID spectrum of the protonated formic acid produced from ethyl formate upon electron ionization and that from $\mathrm{CI}$ of formic acid showed only $\mathrm{HCO}^{+}$and no $\mathrm{H}_{3} \mathrm{O}^{+}$. Holmes et al. [2] reported the ratio $\left(\mathrm{I}_{\mathrm{HCO}+} /\right.$ $\left.\mathrm{I}_{\mathrm{H} 3 \mathrm{O}_{+}}\right)=13$ in their CID spectrum, but gave little information on the details of the experimental conditions used. If protonation occurs on the hydroxyl oxygen, the so-formed $\mathrm{HC}(\mathrm{O}) \mathrm{OH}_{2}^{+}$ion is not expected to survive long - one half vibrational period before rearranging to $\mathrm{OH}_{3}^{+} \ldots \mathrm{CO}(3)$ or more likely, decompose to the dissociated products $\mathrm{H}_{3} \mathrm{O}^{+}+\mathrm{CO}$ (the barrier from $\mathrm{HC}(\mathrm{O}) \mathrm{OH}_{2}^{+}$to $\mathrm{OH}_{3}^{+} \ldots \mathrm{CO}$ is only a few $\mathrm{kJmol}^{-1}$, see Figure 1). In the case our mass selected ion beam should contain any $\mathrm{OH}_{3}^{+} \ldots \mathrm{CO}$, we would expect $\mathrm{H}_{3} \mathrm{O}^{+}$formation upon CID, in accordance with the findings of Schalley et al. Thus the only consistent conclusion to be made is that the beam of ions with $\mathrm{m} / \mathrm{z}$ 47 used to obtain our MI and CID spectra is pure ( $>99$ $\%) \mathrm{HC}(\mathrm{OH})_{2}^{+}$. The observation of an intense peak due to $\mathrm{H}_{3} \mathrm{O}^{+}$in the MI spectrum shows that not only $\mathrm{HCO}^{+}$ but also $\mathrm{H}_{3} \mathrm{O}^{+}$are produced from this precursor upon spontaneous unimolecular decomposition of ions having energy close to the energetical threshold, i.e., via TS(1/2). This conclusion is also consistent with identical appearance energies for $\mathrm{HCO}^{+}$and $\mathrm{H}_{3} \mathrm{O}^{+}$[2].

\section{FT-ICR Experiments}

The abundance of ions in the ICR cell as a function of time were analyzed by a simultaneous nonlinear curve fitting method based on the kinetic scheme shown below (Scheme 2). A typical result for a plot can be found on Figure A1. In this scheme, $[\mathrm{HCOOH}] \mathrm{H}^{+}$represents protonated formic acid which does not decompose further. We assume that the ratio of the bimolecular rate coefficients $k_{3} / k_{2}$ is equal to the ratio of the corresponding unimolecular $\mathrm{k}_{\mathrm{HCO}+} / \mathrm{k}_{\mathrm{H} 3 \mathrm{O}+}=\left(\mathrm{I}_{\mathrm{HCO}+} / \mathrm{I}_{\mathrm{H} 3 \mathrm{O}+}\right)_{\mathrm{p}=0}$. 


$$
\begin{gathered}
\mathrm{HCl}^{+}+\mathrm{HCOOH} \longrightarrow \mathrm{HCl}+\mathrm{HCOOH}^{+} \quad \Delta \mathrm{H}_{\mathrm{r}}=-137 \mathrm{~kJ} / \mathrm{mol} \\
\mathrm{HCl}^{+}+\mathrm{HCOOH} \longrightarrow \mathrm{H}_{2}+\mathrm{Cl}+\mathrm{HCOO}^{+} \quad \Delta \mathrm{H}_{\mathrm{r}}=-49 \mathrm{~kJ} / \mathrm{mol} \\
\text { Scheme 3 }
\end{gathered}
$$

In practice, additional ions to those shown in Scheme 1 were observed. The most abundant were $\mathrm{HCOOH}^{+}$ and $\mathrm{HCOO}^{+}$, in particular for $\mathrm{M}=\mathrm{Cl}$ for which they account for almost $10 \%$ of the total ion current due to the following reactions (Scheme 3). These reaction products will of course affect the amount of $\mathrm{H}_{3} \mathrm{O}^{+}$and $\mathrm{HCO}^{+}$. A direct plot of the temporal dependence of the abundance ratio $\mathrm{I}_{\mathrm{HCO}+} / \mathrm{I}_{\mathrm{H} 3 \mathrm{O}+}$ extrapolated to $\mathrm{t}=0$ should in principle provide the same information. As expected, the agreement between the two values is good, but the direct plot is quite affected by noise (low signal intensities) at short reaction times, which makes it difficult to extrapolate to $t=0$. For this reason the results obtained from the curve fitting will be used in the following.

The ratio $k_{3} / k_{2}$ is weakly dependent upon the formic acid pressure (Figure A2). This is probably owing to some collisionally-induced decomposition of $[\mathrm{HCOOH}] \mathrm{H}^{+}$ into $\mathrm{HCO}^{+}$and $\mathrm{H}_{2} \mathrm{O}$ (vide ante). In order to obtain $\mathrm{k}_{\mathrm{HCO}+} / \mathrm{k}_{\mathrm{H} 3 \mathrm{O}+}=\left(\mathrm{I}_{\mathrm{HCO}+} / \mathrm{I}_{\mathrm{H} 3 \mathrm{O}+}\right)_{\mathrm{p}=0}$, the ratios of ion signals were obtained at three different pressures of formic acid and were extrapolated to zero pressure. The ratio $\left(\mathrm{I}_{\mathrm{HCO}+} / \mathrm{I}_{\mathrm{H} 3 \mathrm{O}+}\right)_{\mathrm{p}=0}$ thus obtained are plotted against $\triangle P A$ in Figure 4 . The value of $\triangle P A$ is an approximate measure of the excess energy of the incipient protonated formic acid. Strictly speaking, the amount of energy deposited in protonated formic acid depends on the detailed mechanism and dynamics of the proton transfer reaction [37]. However, for strongly exothermic proton transfer reactions like those concerned here, experiments [38, 39], and dynamics calculations [40, 41] showed that the large amount of the available energy is deposited in the ionic product upon proton transfer.

In Figure 4 , the ratio $\left(\mathrm{I}_{\mathrm{HCO}+} / \mathrm{I}_{\mathrm{H} 3 \mathrm{O}+}\right)_{\mathrm{p}=0}$ varies approximately linearly with $\triangle P A$, and the ratio ap-

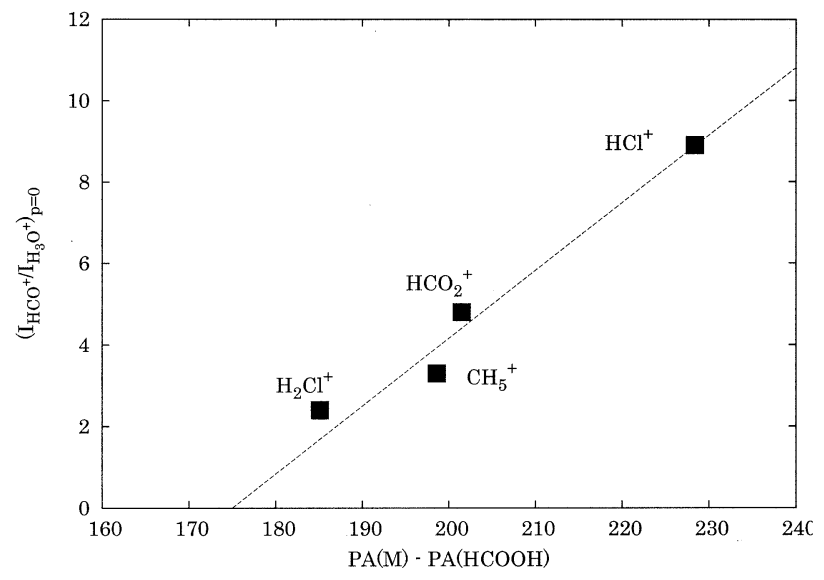

Figure 4. Plot of the relative intensities of the two ionic products $\left(\mathrm{I}_{\mathrm{HCO}+} / \mathrm{I}_{\mathrm{H} 3 \mathrm{O}+}\right)_{\mathrm{p}=0}$ versus the maximum internal energy $\Delta P A$. See text for details.
Table 2. Product distributions from the trajectory calculation

\begin{tabular}{lcc}
\hline & \multicolumn{2}{c}{ Products (\%) } \\
\cline { 2 - 3 } Temperature & $\mathrm{H}_{3} \mathrm{O}^{+}+\mathrm{CO}$ & $\mathrm{HCO}^{+}+\mathrm{H}_{2} \mathrm{O}$ \\
\hline \hline $298 \mathrm{~K}$ & 60 & 40 \\
$1000 \mathrm{~K}$ & 40 & 60 \\
\hline
\end{tabular}

proaches zero for $\triangle P A \approx 175 \mathrm{kJmol}^{-1}$. This energy value is close to the energy difference between the product $\mathrm{HCO}^{+}+\mathrm{H}_{2} \mathrm{O}$ and $\mathrm{HC}(\mathrm{OH})_{2}^{+}$. If the excess energy is less than this, $\mathrm{HCO}^{+}$cannot be produced, and the ratio $\left(\mathrm{I}_{\mathrm{HCO}+} / \mathrm{I}_{\mathrm{H} 3 \mathrm{O}+}\right)_{\mathrm{p}=0}$ should become zero. An RRKM calculation which includes the tunnel effect shows that the unimolecular dissociation of $\mathrm{HC}(\mathrm{OH})_{2}^{+}$ commences from ca. $20 \mathrm{kJmol}^{-1}$ below $\mathrm{TS}(\mathbf{1} / 2)$, for which the rate coefficient is $1 \%$ of its value at the TS(1/2) energy.

The experiment and the analysis become difficult for proton donors with $\triangle P A$ less than that of $\mathrm{H}_{2} \mathrm{Cl}^{+}$, due to extremely low product abundances. We did the experiment with $\mathrm{HI}^{+}$as a proton donor, for which $\triangle P A$ is $133.8 \mathrm{kJmol}^{-1}$. As expected, the abundance of $\mathrm{HCO}^{+}$ was negligibly low, since $\triangle P A$ is lower than the energy of $\left(\mathrm{HCO}^{+}+\mathrm{H}_{2} \mathrm{O}\right)$ and also lower than $\mathbf{T S}(\mathbf{1} / \mathbf{2})$, but above the energy of $\left(\mathrm{H}_{3} \mathrm{O}^{+}+\mathrm{CO}\right)$. The abundance of $\mathrm{H}_{3} \mathrm{O}^{+}$was also negligibly low, in spite of the fact that there should be sufficient energy for its formation. If some protonation occurs on the hydroxyl oxygen, formation of $\mathrm{H}_{3} \mathrm{O}^{+}$should be observed. Again, the evidence is in favor of a mechanism where $\mathrm{H}_{3} \mathrm{O}^{+}$, as well as $\mathrm{HCO}^{+}$, is formed from $\mathrm{HC}(\mathrm{OH})_{2}^{+}$via $\mathbf{T S}(\mathbf{1 / 2})$.

\section{Dynamics Calculations}

In order to get better insight into the dynamical factors which determine whether the ionic product is the formyl cation (6) or the hydroxonium ion (4), we conducted two series of direct dynamics calculations, one corresponding to an ensemble at $298 \mathrm{~K}$ and one at 1000 K. For each temperature a total of 30 different trajectories were calculated, all starting at the transition state, TS(1/2). We would like to emphasize that these conditions were not chosen to quantitatively reproduce the experiments-neither the two different MI experiments, nor any of the five different FT-ICR experiments. The main purpose is to study the variation of the product distribution with energy/temperature.

Trajectory calculations of the kind used in this work are demanding in terms of computational resources. One single trajectory requires the calculation of the wave function and its derivatives at a large number of points. By using MP2(fc)/6-31G(d) we achieve a satisfying compromise between computer time and chemical accuracy. As already mentioned, the MP2(fc)/6$31 \mathrm{G}(\mathrm{d})$ energies compare quite well with the G2 energies (Figure 1).

Table 2 summarizes the dynamics calculations. At low temperature, the trajectories which give $\mathrm{H}_{3} \mathrm{O}^{+}$ 


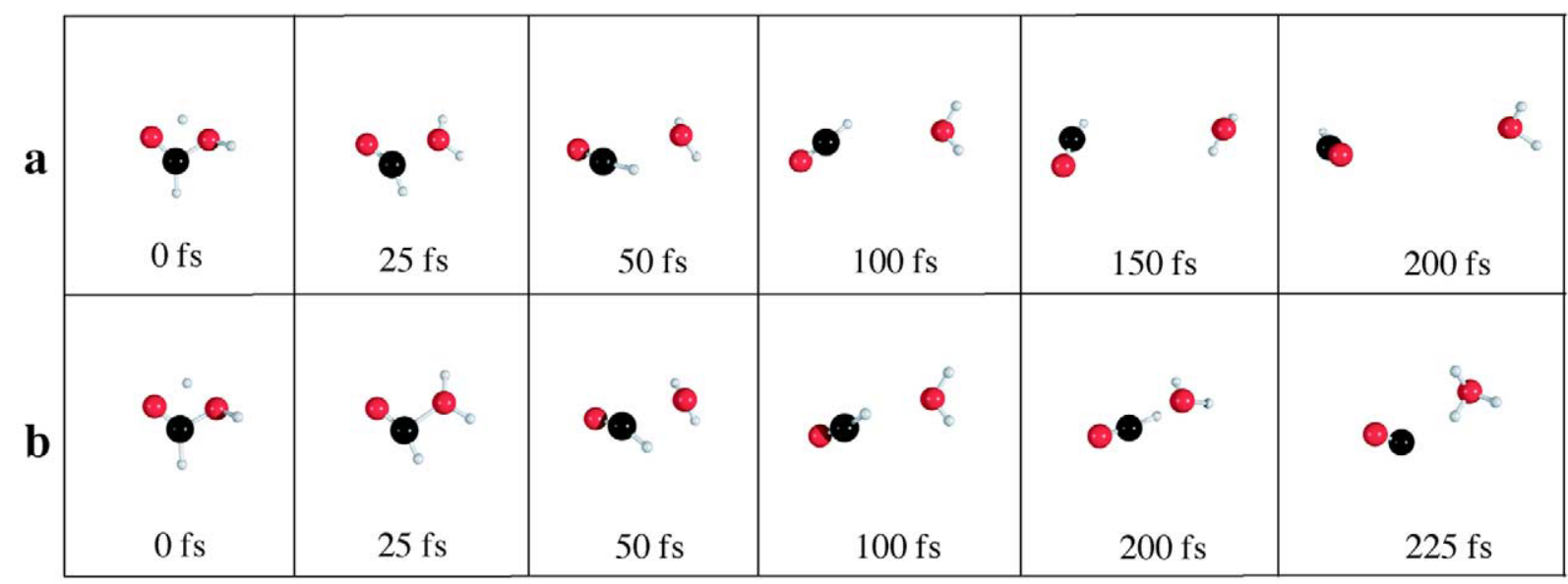

Figure 5. Snapshots from two reaction trajectories, giving (a) the formyl cation and (b) the hydroxonium ion as product.

dominate, while at high temperature $\mathrm{HCO}^{+}$becomes the more abundant. This finding is consistent, at least qualitatively, with the experimental results. For successful formation of $\mathrm{HCO}^{+}$it is necessary that $\mathrm{H}_{2} \mathrm{O}$ can slip away from $\mathrm{HCO}^{+}$before the subunits can reorient for the more basic $\mathrm{H}_{2} \mathrm{O}$ to pick up the proton. The MP2/6-31G(d) harmonic vibrational frequency of the long $\mathrm{C}-\mathrm{O}$ bond in 2 (Figure 2), is $267 \mathrm{~cm}^{-1}$. This corresponds to a vibrational period slightly above 100 $\mathrm{fs}$, which gives a rough estimate of the time period which is available for the transient $\mathrm{HC}(\mathrm{O}) \mathrm{OH}_{2}^{+}$(2) to expel a water molecule directly with low risk for picking up a proton. It is also essential that the velocity of the water molecule is sufficiently high to escape the attractive ion/molecule potential. Otherwise, the water molecule will return and a second encounter between water and $\mathrm{HCO}^{+}$increases the chance for proton transfer to water significantly. Inspection of the individual trajectories confirms this idea [42]. At both temperatures formation of free $\mathrm{HCO}^{+}(10 \AA$ separation) is usually completed within $200 \mathrm{fs}$. On the other hand, $\mathrm{H}_{3} \mathrm{O}^{+}$formation typically commences on a longer timescale. Two or more re-encounters between the two units leads to quite long life-times of the ion/molecule complex, often exceeding 1 ps. Figure 5 illustrates the two situations. It should also be mentioned that on the average those trajectories giving rise to $\mathrm{HCO}^{+}$formation has significantly higher rotational energy than those giving $\mathrm{H}_{3} \mathrm{O}^{+}$, indicating a centrifugal effect.

We want to emphasize that the dynamic situation described here can not simply be explained as being attributable to a process often depicted as a rate determining isomerization giving a relatively long-lived ion/molecule complex which eventually dissociates after rearrangement. The key point is that the life-time of the complex is not constant, since short life-times give one product (the thermochemically less stable), while longer life-times give the more stable. The critical factor is the energy and phase of the $\mathrm{C}-\mathrm{O}$ stretch, which is a random variable being implicitly given from the initial conditions. This is essentially a kinematic effect, in contrast to the situation in a previous example where two product channels from a single transition state are due to the detailed topology of the potential energy surface [43].

\section{Conclusions}

The findings of this study can be summarized in the following points.

1. In the MI spectrum of protonated formic acid, both $\mathrm{HCO}^{+}$and $\mathrm{H}_{3} \mathrm{O}^{+}$are observed. The abundance ratio $\mathrm{I}_{\mathrm{HCO}+} / \mathrm{I}_{\mathrm{HzO}+}$ appears to increase with energy.

2. In the FT-ICR experiment, the ratio $\left(\mathrm{I}_{\mathrm{HCO}+} /\right.$ $\left.\mathrm{I}_{\mathrm{H} 3 \mathrm{O}+}\right)_{\mathrm{p}=0}$ increases with increasing excess energy of the protonated formic acid.

3. Protonation occurs only on the carbonyl oxygen of formic acid.

4. Both $\mathrm{H}_{3} \mathrm{O}^{+}$and $\mathrm{HCO}^{+}$are formed via TS(1/2).

5. The outcome of the ab initio direct dynamics calculations is consistent with the experiments. Kinematic effects already at the TS determine the life-time of the ion molecule complex, and thereby the product. Short life-times support the high energy $\mathrm{HCO}^{+}$.

\section{Acknowledgments}

The authors thank The Research Council of Norway (Program for Supercomputing, NOTUR) for computer time.

\section{References}

1. Mackay, G. I.; Hopkinson, A. C.; Bohme, D. K. J. Am. Chem. Soc. 1978, 100, 7460-7464.

2. Holmes, J. L.; Mommers, A. A.; De Koster, C.; Heerma, W.; Terlouw, J. K. Chem. Phys. Lett. 1985, 115, 437-440.

3. Tajima, S.; Fujizuka, A.; Nakajima, S.; Takahashi, Y.; Sckiguchi, O. Rapid Commun. Mass Spectrom. 2000, 14, 1195-1199.

4. Hopkinson, A. C.; Yates, K.; Csizmadia, I. G. J. Chem. Phys. $1970,52,1784-1789$. 
5. Srikanth, R.; Bhanuprakash, K.; Srinivas, R.; Wong, C. Y.; Terlouw, J. K. J. Mass Spectrom. 2004, 39, 303-309.

6. Cheung, Y.-S.; Li, W.-K. J. Mol. Struct. (Theochem). 1995, 333, 135-145

7. Glosik, J.; Jordan, A.; Skalsky, V.; Lindinger, W. Int. J. Mass Spectrom. Ion Processes 1993, 129, 109-116.

8. Olah, G. A.; White, A. M. J. Am. Chem. Soc. 1967, 89, 3591.

9. Minkwitz, R.; Schneider, S.; Seifert, M.; Hartl, H. Zeitschrift für Anorganische und Allgemeine Chemie 1996, 622, 1404-1410.

10. Frisch, M. J.; Trucks, G. W.; Schlegel, H. B.; Scuseria, G. E.; Robb, M. A.; Cheeseman, J. R.; Zakrzewski, V. G.; Mongomery, J. A.; Stratmann, R. E.; Burant, J. C.; Dapprich, S.; Millam, J. M.; Daniels, A. D.; Kudin, K. N.; Strain, M. C.; Farkas, O.; Tomasi, J.; Barone, V.; Cossi, M.; Cammi, R.; Mennucci, B.; Pomelli, C.; Adamo, C.; Clifford, S.; Ochterski, J.; Petersson, G. A.; Ayala, P. Y.; Cui, Q.; Morokuma, K.; Malick, D. K.; Rabuck, A. D.; Raghavachari, K.; Foresman, J. B.; Cioslowski, J.; Ortiz, J. V.; Baboul, A. G.; Stefanov, B. B.; Liu, G.; Liashenko, A.; Piskorz, P.; Komaromi, I.; Gomperts, R.; Martin, R. L.; Fox, D. J.; Keith, T.; Al-Laham, M. A.; Peng, C. Y.; Nanayakkara, A.; Gonzalez, C.; Challacombe, M.; Gill, P. M. W.; Johnson, B. G.; Chen, W.; Wong, M. W.; Andres, J. L.; Gonzales, A.; Head-Gordon, M.; Replogle, E. S.; Pople, J. A. Gaussian 98; Gaussian Inc.: Pittsburgh, PA, 1998.

11. Scott, A. P.; Radom, L. J. Phys. Chem. 1996, 100, 16502.

12. Gonzales, C.; Schlegel, H. B. J. Phys. Chem. 1989, 90, 2154.

13. Curtiss, L. A.; Raghavachari, K.; Trucks, G. W.; Pople, J. A. J. Chem. Phys. 1991, 94, 7221.

14. Helgaker, T.; Uggerud, E.; Jensen, H. J. A. Chem. Phys. Lett. 1990, 173, 145-150.

15. Chen, W.; Hase, W. L.; Schlegel, H. B. Chem. Phys. Lett. 1994, $228,436-442$.

16. Bakken, V.; Millam, J. M.; Schlegel, H. B. J. Chem. Phys. 1999, $111,8773-8777$

17. Millam, J. M.; Bakken, V.; Chen, W.; Hase, W. L.; Schlegel, H. B. J. Chem. Phys. 1999, 111, 3800-3805.

18. Hase, W. L. In Encyclopedia of Computational Chemistry. Schleyer, P. v. R.; Allinger, N. L.; Clark, T.; Gasteiger, J.; Kollmann, P. A.; Schaefer, H. F., III; Schreiner, P. R., Eds.; J. Wiley and Sons Ltd.: Chichester, 1998, pp 402-407.

19. Hvistendahl, G.; Uggerud, E. Org. Mass Spectrom. 1991, 26, 67-73.

20. Pritchard, H.; Thynne, J. C. J.; Harrison, A. G. Can. J. Chem. 1968, 46, 2141-2146.

21. Freeman, C. G.; Harland, P. W.; McEwan, M. J. Austr. J. Chem. 1978, 31, 2157-2160.

22. Villinger, H.; Saxer, A.; Richter, R.; Lindinger, W. Chem. Phys. Lett. 1978, 96, 513-516.

23. Villinger, H.; Richter, R.; Lindinger, W. Int. J. Mass Spectrom. Ion Phys. 1983, 51, 25-30.

24. Villinger, H.; Saxer, A.; Bryant, H.; Lindinger, W. Proceedings of the 16th International Conference on Phenom. Ioniz. Gases; 1983, pp 572-573.

25. Schalley, C. A.; Schroeder, D.; Schwarz, H. Int. J. Mass Spectrom. Ion Processes 1996, 153, 173-199.

26. Ha, T. K.; Nguyen, M. T. J. Phys. Chem. 1984, 88, 4295-4298.

27. Lopez, R.; Rio, E. D.; Menendez, M. I.; Sordo, T. L. J. Comput. Chem. 1999, 20, 1432-1443.

28. Lias, S. G.; Rosenstock, H. M.; Deard, K.; Steiner, B. W.; Herron, J. T.; Holmes, J. H.; Levin, R. D.; Liebman, J. F.; Kafafi, S. A.; Bartmess, J. E.; Hunter, E. F.; Linstrom, P. J.; Mallard, W. G. In NIST Chemistry Webbook; (http://webbook.nist.goc/ chemistry), 2002.

29. Hogeveen, H. Recueil des Travaux Chimiques des Pays-Bas 1968, 87, 1313-1317.

30. Hogeveen, H.; Mackor, E. L.; Ros, P.; Schachtschneider, J. H. Recueil des Travaux Chimiques des Pays-Bas 1968, 87, 1057-1064.
31. Ros, P. J. Chem. Phys. 1968, 49, 4902-4916.

32. Benoit, F. M.; Harrison, A. G. J. Am. Chem. Soc. 1977, 99, 3980-3984.

33. Bagno, A.; Scorrano, G. J. Phys. Chem. 1996, 100, 1536-1544.

34. Windus, T. L.; Gordon, M. S. J. Am. Chem. Soc. 1991, 113, $4356-4357$

35. Windus, T. L.; Gordon, M. S. Theor. Chim. Acta. 1992, 83, 21-30.

36. Minyaev, R. M.; Wales, D. J. J. Chem. Phys. 1994, 98, 7942-7944.

37. Lin, H. Y.; Ridge, D. P.; Vulpius, T.; Uggerud, E. J. Am. Chem. Soc. 1994, 116, 2996.

38. Zwier, T. S.; Bierbaum, V. M.; Ellison, G. B.; Leone, S. R. J. Chem. Phys. 1980, 5426.

39. Weisshaar, J. C.; Zwier, T. S.; Leone, S. R. J. Chem. Phys. 1981, $75,4873$.

40. Bueker, H. H.; Uggerud, E. J. Phys. Chem. 1995, 99, 5945.

41. Bueker, H.-H.; Helgaker, T.; Ruud, K.; Uggerud, E. J. Phys. Chem. 1996, 100, 15388.

42. Bakken, V. (http://folk.uio.no/vebjornb/work/hcooh2+/), 2004.

43. Bakken, V.; Danovich, D.; Shaik, S.; Schlegel, H. B. J. Am. Chem. Soc. 2001, 123, 130-134.

\section{Appendix}

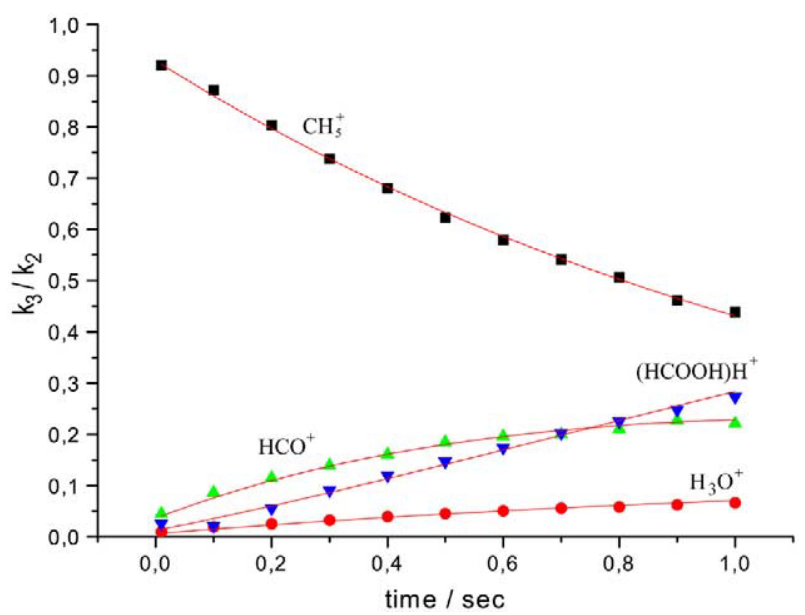

Figure A1. Typical result of curve fitting. In this case, the ratio $\mathrm{k}_{3} / \mathrm{k}_{2}=4.7$. Proton donor $\mathrm{CH}_{5}{ }^{+}$at a $\mathrm{HCOOH}$ pressure of $\mathrm{p}=8.1$ $\times 10^{-9}$ mbar.

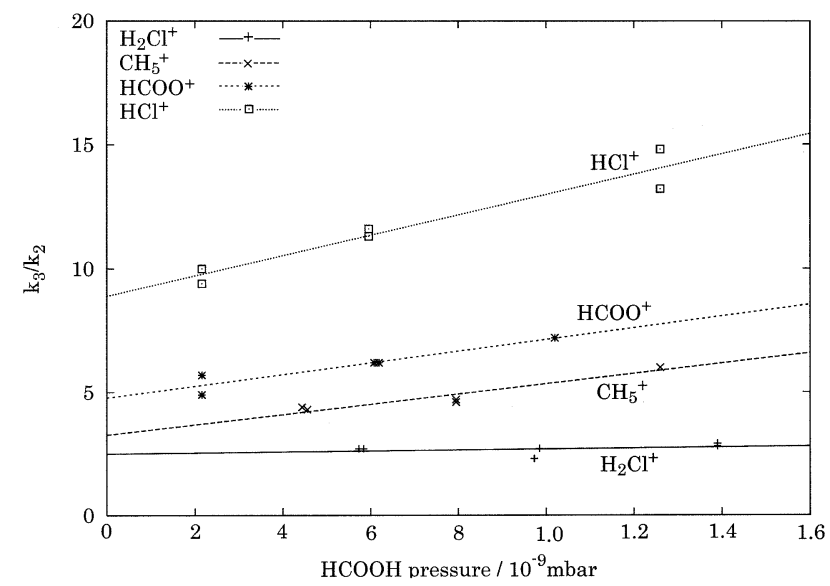

Figure A2. Pressure dependence of $k_{3} / k_{2}$ obtained from curve fittings. 